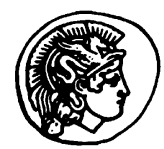

PERGAMON

\title{
Pausal behavior of end-users in online searching
}

\author{
Mu-hsuan Huang * \\ Department of Library and Information Science, National Taiwan University, Taipei 106, Taiwan, ROC \\ Received 6 August 2001; accepted 29 May 2002
}

\begin{abstract}
This research used an information processing approach to analyze the pausal behavior of end-users. It is based on viewing the search as a series of actions and pauses (rests). The end-users are 41 students and 3 faculty. After instructions, subjects searched through the semester, doing 79 searches. This study identified reasons for pausing, location of pauses, hesitation rate and pausal behavior changes over time. This study confirms that the searchers pauses less frequently and for shorter periods as they progressed through searches with more experience and practice, searchers moved more smoothly online, and the hesitation rate decreased over time. Over a series of searches or cycles within long searches, searchers gradually began to chunk more information between pauses. However, the duration of pauses do not vary significantly over time.

(C) 2002 Elsevier Science Ltd. All rights reserved.
\end{abstract}

Keywords: Online searching; Information behavior; Information retrieval; Pausal behavior

\section{Introduction}

During an online search, a searcher alternates between two states: the move or active state, and the pause or rest state. In the move or active state, a searcher issues a command or makes a statement. Conversely, at the pause or rest state, a searcher thinks or does something else instead of moving. An almost imperceptible pause may indicate that the searcher has anticipated all cognitive decisions or that the decisions require minimal effort. On the other hand, an obvious pause may reflect the searcher's need to concentrate more cognitive effort on making a decision, possibly because of its complexity, novelty, or unexpectedness.

Most online studies have emphasized the move or active states. Yet pausal behavior reflects the cognitive effort involved in decision-making and is an inherently more refined approach to understanding information processing in online searchers than error analysis in move states. In a

\footnotetext{
*Fax: +886-2-2363-2859.

E-mail address: mhhuang@ccms.ntu.edu.tw (M. Huang).
} 
preliminary analysis of the data in this study, only about $10 \%$ of the pauses were related to errors. Other researchers have studied pausal behavior in silent reading, writing, and problem-solving as a way of determining decision making (Foulin, 1998; Tavalin, 1995). According to Carter, Ruggels, Jackson, and Heffner (1973, p. 31), readers stopped or paused most frequently to think, to reread, to express confusion, to ask an unspecified question, to seek clarification, to make critical comments, and to refer to earlier material. Grunig found that readers stopped when they could not process words into a cognitive structure, when they disagreed with an evaluation or the evaluative implications of a condition. He later modified his reasons to "because of confusion, to reread, to ask a question, to think about an idea, because you understand (i.e. to assimilate an idea), to agree, and to disagree" (Grunig, 1985).

Since most studies of online behavior have emphasized the active states in a search, little is known about pausal behavior during a search. Consequently, this article emphasizes answering some basic questions about pausal behavior of end-users as they search. This research addresses several questions: (1) How frequently does a person pause within a search? (2) For how long does he pause? (3) Why does he pause? (4) Does the length of the pause vary according to why he is pausing? (5) Where does he pause, i.e., during or at the end of a move, and in what moves? (6) What is the size of the chunk of information being processed? (7) Does the pausal behavior change over time as searchers gain experience with searching tasks?

\section{Methodology}

\subsection{Subjects}

The study is based on observing the behavior of end-users over an entire semester. Obtained through convenience sampling, the 44 subjects included $7(15.9 \%)$ undergraduates, $3(6.8 \%)$ faculty, and $34(77.2 \%)$ graduate students (including 1 post-doctorate) in a wide range of disciplines from University of Maryland. Generally speaking, subjects came from 16 different majors in the University. Among them, $12(27 \%)$ were from history and $10(23 \%)$ were from the Department of Agricultural and Resources Economics, only $3(6.8 \%)$ subjects came from College of Library and Information Services. About $75 \%$ of the subjects had used computers before, primarily for word-processing, although about 23-32\% indicated familiarity with spreadsheets, programming, or another software application. Half had used a CD-Rom search experience before, but only $5(11.3 \%)$ had used the Dialog system before. A special search service was established, and the subjects were allowed to search their own search requests throughout a semester at no charge. They were required to use the Dialog search system's command language. Before searching, the seven undergraduates received training in class, the others via a half-hour videotape. The videotape contained the same materials presented in class training. Also, these two instructions are distributed by the same person (not the researcher).

\subsection{Data}

Data consist of 79 different searches done by these searchers, 19 of whom did two to eight searches during the semester. Before each search session, a searcher completed a brief online 
questionnaire to provide information on the natural language query, context of search, previous information gathering, and the subject's assessment of the probability of finding information on the topic. In addition, before his first search, each subject completed a questionnaire providing information about personal characteristics, such as academic status and major, and experience with computers, CD-Rom searching, and Dialog searching. In each search session, a subject searched on his own and was observed. The observer made no comments during the search, but a one-page help sheet was always available. The subjects also had access to Dialog's file-specific help sheets. The subjects did not know their timed keystrokes were captured automatically. The study did not gather thinking-aloud protocols because rambling thoughts would have affected timing, which was critical in this research.

The observer noted pauses and recorded her perceptions of the reasons for them. After the search, while the user's output was being printed, the same observer analyzed the keystroke log with a computer program that marked pauses of 3 seconds or longer. Fig. 1 illustrates an example of search commands. It is only a very small part of the subject's search. Extracting from the same search, Fig. 2 shows an example of computer output marked pauses. The same search keys wrap around form the first column to the second column. In Fig. 2, the ones marked@@@@indicate pauses of 3 seconds or longer. As a matter of fact, there are four pauses of 3 seconds or longer in Fig. 2. Then the observer went through the processed keystroke data with the subject to obtain the searcher's rationale for each pause of 3 seconds or longer. The researcher's observations and the post-search interviews provided corroborative data. Where they deviated, the interview data were accepted.

In analyzing the data, the emphasis was on the pauses a searcher made while searching. A pause is defined as a discernible stop of 3 or more seconds during the time a person is issuing search commands. A total of 2404 pauses 3 seconds or longer were identified. The study investigated only pauses that occurred while a searcher was issuing commands; it did not cover pauses when the computer was displaying information. Also, this study did not cover system response time and users' reading time. Because the timed keystroke logs reveal only when a user pauses in typing his search statements, they cannot indicate when a user pauses while a computer is displaying information.

\section{Analysis and results}

Each pause was coded for length of time, the reason for pausing, location in the search by move (system command) and element (part of multi-part command), and the size of the chunk of information preceding it by number of elements. In this study, the searches varied considerably in subject, objective, database, and strategy, since they reflected actual information needs. They ranged from searches emphasizing precision, such as verifying items for a bibliography, to

b 622

ss zaibatsu

d s1/3/all

d s1/5/all

Fig. 1. A search command example. 


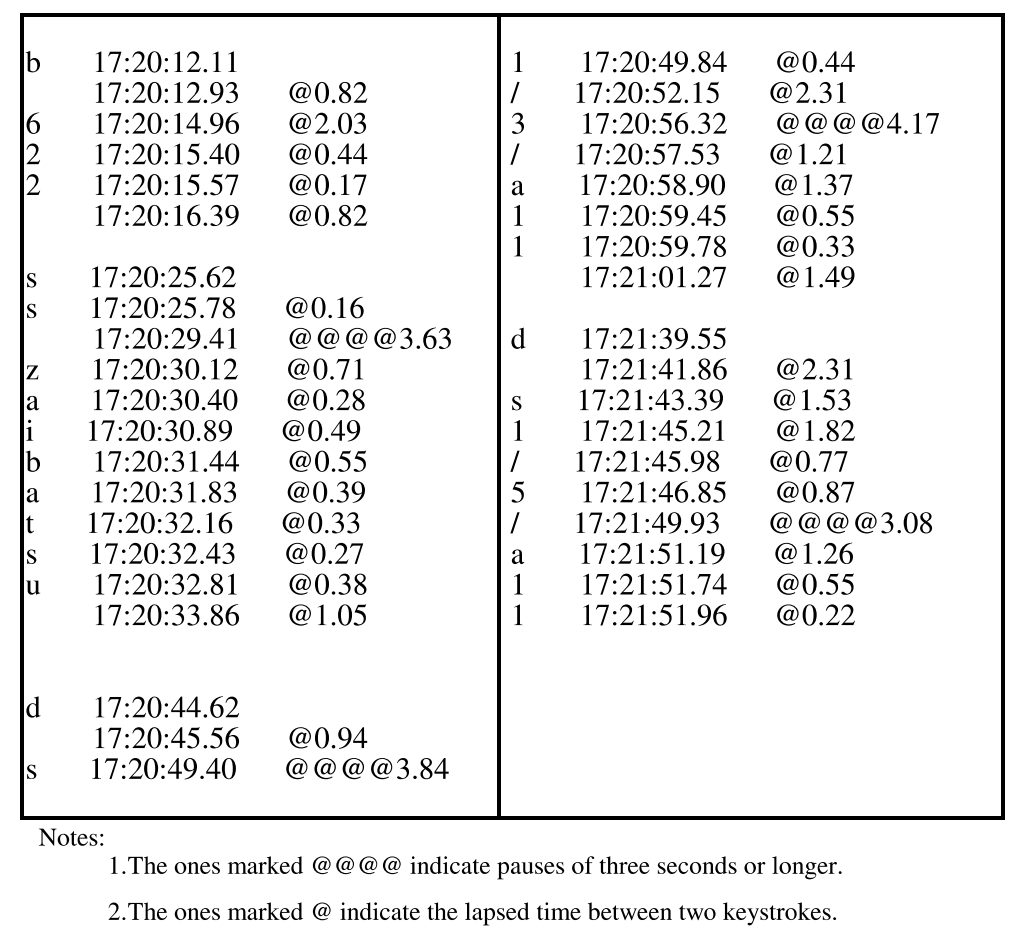

Fig. 2. An example of computer output marking pauses.

retrospective searches for all possible materials on a particular topic. As a result, they also differed considerably in length. Preliminary analysis indicated a close relationship between the frequency of pauses and the length of the search. Because of this, the searches were divided into cycles, as in Saracevic, Kantor, Chamis, and Trivison (1988, p. 170), to reduce the effect of search length on other characteristics. A cycle is defined as a cohesive unit of a search, which consists of all consecutive moves up to, and including one or more print commands. For example, a cycle may start with "begin" or "select" (one "select" command or several "select" commands) and with one or several print commands. Fig. 1 also shows an example of a typical cycle. In this study, the 79 searches in this study yielded 468 cycles.

A search consists of cycles which, in turn, are composed of commands or moves. Commands or moves are composed of elements. During a search, a searcher pauses at various times during the search in connection with processing an amount of information, referred as a chunk of information. In this study, the aspects of pausal behavior considered are: frequency of pauses, duration of pauses, and reasons for pausing, location of pauses. Also addressed are the amount of information being processed, hesitation rate, relationship between reasons for pausing and length of pause, hesitation rate, and changes in pausal behavior over time.

\subsection{Frequency of pauses}

The number of pauses within a search ranged from 1 to 143 . On average, a searcher pauses 30.43 times (with a standard deviation of 24.29) in a search. Although some extreme numbers 
existed, most of the searches had 1-30 pauses (61\%). Because the frequency of pause is highly associated with length of a search, breaking a search into cycles helps to reduce the effect of the length of search time. A cycle involved, on average, 5.14 pauses and a standard deviation of 5.6 (67.8\%). In general, almost two-thirds of the pauses fell into the range of $0-5$ and over $95 \%$ of the pauses fell into the range of $0-15$ (see Table 1 for detailed information).

\subsection{Duration of pauses}

Table 2 shows the frequency distribution of the duration of pauses. The range is large, from 3 seconds to slightly more than 3 minutes, but the distribution is skewed toward short pauses. Almost $80 \%$ were within the range of $3-10$ seconds $(1920,79.9 \%)$ and $92.6 \%$ (2227) of the pauses were within 20 seconds. The average length of a pause was 8.4 seconds and the standard deviation was 10.3 seconds.

\subsection{Reasons for pausing}

The interview data revealed 250 different reasons for pausing. The subjects phrased their comments very specifically, usually in terms of the action they were involved in, and frequently mentioned specific commands, features, or elements. About half the reasons occurred only once or twice (89 times, 36\%) (44 times, 18\%). Table 3 lists 15 reasons cited most frequently by the searchers. The results indicate that the pauses occurred most frequently because subjects were confused about the print format (198 times, $8 \%$ ) or which set to print (189 times, 8\%); wondered which term to use (162 times, 7\%); or verified search statements (132 times, 6\%). Other pauses occurring frequently were caused by confusion about a database number, a set number previously created (for "ss" commands, not for "print" commands), how to "display" (general syntax problem), how to display a range of items, which items to print, using the Boolean operator

Table 1

Frequency distribution of pauses by cycles

\begin{tabular}{lcc}
\hline Number of pauses per cycle & Number of cycles & \% of total cycles \\
\hline $0-5$ & 317 & 67.8 \\
0 & 45 & 9.6 \\
1 & 85 & 18.2 \\
2 & 67 & 14.3 \\
3 & 51 & 10.9 \\
4 & 43 & 9.2 \\
5 & 26 & 5.6 \\
$6-10$ & 82 & 17.5 \\
$11-15$ & 47 & 10.0 \\
$16-20$ & 8 & 1.7 \\
$21-25$ & 7 & 1.5 \\
$26-30$ & 5 & 1.1 \\
$31-35$ & 2 & 0.4 \\
Total & 468 & 100.0 \\
\hline
\end{tabular}


Table 2

Frequency distribution of duration of pause

\begin{tabular}{lcc}
\hline Duration of pauses $(\mathrm{s})$ & Number of pauses & \% of total pauses \\
\hline $3-9.99$ & 1920 & 79.9 \\
$3-3.99$ & 749 & 31.2 \\
$4-4.99$ & 429 & 17.8 \\
$5-5.99$ & 285 & 11.9 \\
$6-6.99$ & 183 & 7.6 \\
$7-7.99$ & 112 & 4.7 \\
$8-8.99$ & 94 & 3.9 \\
$9-9.99$ & 68 & 2.8 \\
$10-10.99$ & 307 & 12.8 \\
$20-20.99$ & 101 & 4.2 \\
$30-30.99$ & 33 & 1.4 \\
$40-40.99$ & 15 & 0.6 \\
$50-50.99$ & 11 & 0.5 \\
$60+$ & 17 & 0.7 \\
Total & 2404 & 100.0 \\
\hline
\end{tabular}

Table 3

Most frequently occurring reasons for pausing ranked by frequency

\begin{tabular}{lll}
\hline $\begin{array}{l}\text { Number } \\
\text { of pauses }\end{array}$ & $\begin{array}{l}\text { \% of total } \\
\text { pauses }\end{array}$ & Reasons for pausing \\
\hline 198 & 8.2 & Deciding which print format to use or checking the print format \\
189 & 7.9 & $\begin{array}{l}\text { Determining the set number or checking the set number } \\
\text { Deciding which term to use }\end{array}$ \\
162 & 6.7 & Verifying (proof reading) search statements \\
99 & 5.5 & Checking the set number already created \\
93 & 4.1 & Determining how to display (syntax) \\
76 & 3.9 & Determining which items to print \\
69 & 2.2 & Determining where to truncate \\
62 & 2.6 & Deciding the file number, getting the file number \\
48 & 2.0 & Deciding upon spelling (confused about how to spell it) \\
48 & 2.0 & Composing search statement (formulating search statement) \\
38 & 1.6 & Determining whether to put a space \\
34 & 1.4 & Determining whether to use this term (confirming the term) \\
34 & 1.4 & Determining how to display a specific item or a specific range of items (syntax) \\
32 & 1.3 & Deciding to use "and", making sure to use "and", and wondering whether to use "and" \\
\hline
\end{tabular}

"and", where to truncate, and whether to put a space. The subjects also needed to confirm terms, compose search statements, and react to spelling problems.

Because the majority of online search studies indicate that end-users experienced difficulties in developing good search strategies, it was anticipated that most pauses would concern refining a search, such as responding to too many hits or no postings, deciding to lookup or browse, but the data do not strongly support these as reasons for pausing. Instead, most pauses were related to 
identifying the set number, determining the print format, deciding which term to use, refining search statements, determining the document number, checking spelling, determining how to display, determining which items to print, and deciding where to truncate. Some pauses confirm the deficiencies and problems of end-users identified in other studies, such as problems in selecting an appropriate database (Kirby \& Miller, 1986; Wozny, 1988), selecting terms (Kirby \& Miller, 1986; Walker, McKibbon, Hayes, \& Ramsden, 1991), using truncation (Charles \& Clark, 1990; Trzebiatowske, 1984), choosing print options (Shaw, 1986; Trzebiatowske, 1984; Wozny, 1988), checking spelling errors (Tenopir, 1986), and deciding on Boolean operator (Kirby \& Miller, 1986; Tenopir, 1986; Trzebiatowske, 1984; Wozny, 1988).

\subsection{Location of pauses}

\subsubsection{By element}

In preliminary considerations of where pausing occurred, the researcher had thought that, because most commands, especially those of novice searchers, are short and relatively uncomplicated, a command would serve as the coherent unit for the searcher. Considering a word as an integrated chunk of letters in itself, a command rarely has more than seven chunks. Research has shown that human short-term memories have the capacity for 7 (plus or minus 2) chunks (Miller, 1956). As a result, pauses would occur at the end of a search move or coherent thought, i.e. at the end of the command. In this study, a move was defined before as a system command inclusive of its variable parts. "ss boats or ships," for example, was considered one move, itself composed of some intermediate chunks. Relating pauses to the commands in which they occurred would then give some indications of the tasks which required greater information-processing or were less programmable from the searcher's point of view.

It is apparent that searchers paused within commands, even, in some cases, within words. As a result, it was necessary to use a finer unit of analysis than the move. In selecting the unit, the premise was still to retain a sense of the intermediate chunks. Instead of keystrokes, used in many other studies, the smallest unit of analysis for studies of location adopted in this study is an element, as defined earlier.

Considering this unit, most searchers paused when they were issuing "ss" commands, selecting terms, determining the set number (for both "ss" and "print"), solving logical problems (especially when to use "and" and parentheses), and determining print format and item number for print commands. These elements accounted for 75.7\% (1821) pauses (Table 4).

By analyzing the subjects' comments and noting the location of the element referred to in the comment, it is possible to determine if subjects paused to consider a future action, to assess a previous action, or to think about something they were doing at the time. Most of the pauses $(67 \%$ (1615)) happened as subjects were issuing the element; 23\% (551) of them occurred after searchers finished issuing the element; and only 10\% (238) anticipated an action.

\subsubsection{By moves or commands}

Some elements occur in several commands and some commands incorporate many elements so that the problematic nature of specific commands is obscured somewhat by reporting results only at the element level. Table 5 shows the pause analysis by command. As expected, "select steps" or "select" statements accounted for the majority of the pauses (1273 times, 53\%). Also, "display" 
Table 4

Frequency distribution of pauses by elements

\begin{tabular}{|c|c|c|}
\hline Number of pauses & $\%$ of total pauses & Element \\
\hline 37 & 1.54 & Begin (command part) \\
\hline 75 & 3.12 & Display (command part) \\
\hline 21 & 0.87 & Display Set (command part) \\
\hline 2 & 0.08 & Execute Steps (command part) \\
\hline 4 & 0.17 & Identify Duplication (command part) \\
\hline 25 & 1.04 & Logoff (command part) \\
\hline 5 & 0.21 & Save or Save Temp (command part) \\
\hline 175 & 7.28 & Select Step or Select (command part) \\
\hline 52 & 2.16 & Type (command part) \\
\hline 415 & 17.26 & Terms \\
\hline 7 & 0.29 & AU (field delimiter) \\
\hline 4 & 0.17 & PY (field delimiter) \\
\hline 6 & 0.25 & HP (field delimiter) \\
\hline 1 & 0.04 & LA (field delimiter) \\
\hline 1 & 0.04 & AN (field delimiter) \\
\hline 4 & 0.17 & $\mathrm{CO}$ (field delimiter) \\
\hline 2 & 0.08 & DE (field delimiter) \\
\hline 8 & 0.33 & TI (field delimiter) \\
\hline 1 & 0.04 & SU (field delimiter) \\
\hline 50 & 2.08 & $\begin{array}{l}\text { Values of prefix part (such as accession } \\
\text { number) }\end{array}$ \\
\hline 115 & 4.78 & Sets already created (for ss) \\
\hline 52 & 2.16 & Database number \\
\hline 4 & 0.17 & Other variables parts \\
\hline 113 & 4.70 & AND \\
\hline 33 & 1.37 & OR \\
\hline 3 & 0.12 & NOT \\
\hline 120 & 4.99 & (,or) [parentheses] \\
\hline 59 & 2.45 & Truncation (?) \\
\hline 2 & 0.08 & W (proximity operator) \\
\hline 5 & 0.21 & $\mathrm{~N}$ (proximity operator) \\
\hline 6 & 0.25 & $\begin{array}{l}\text { Number of words to allow with proximity } \\
\text { operator }\end{array}$ \\
\hline 175 & 7.28 & Enter \\
\hline 24 & 1.00 & , (punctuation) \\
\hline 2 & 0.08 & $>$ (punctuation) \\
\hline 15 & 0.62 & $=($ punctuation $)$ \\
\hline 142 & 5.91 & / (punctuation) \\
\hline 14 & 0.58 & - (punctuation) \\
\hline 2 & 0.08 & . (punctuation) \\
\hline 289 & 12.02 & Set numbers (for display) \\
\hline 170 & 7.07 & Print numbers \\
\hline 107 & 4.45 & Document numbers \\
\hline 35 & 1.46 & All \\
\hline 1 & 0.04 & TI (print format) \\
\hline 21 & 0.87 & Null elements \\
\hline 2404 & 100 & Total \\
\hline
\end{tabular}


Table 5

Frequency distribution of pauses by moves

\begin{tabular}{lcl}
\hline Number of pauses & \% of total pauses & Move \\
\hline 114 & 4.74 & Begin \\
1273 & 52.95 & Select steps or select \\
567 & 23.59 & Display \\
333 & 13.85 & Type \\
1 & 0.04 & Expand \\
40 & 1.66 & Display sets \\
5 & 0.21 & Execute step \\
6 & 0.25 & Identify duplication and remove duplication \\
6 & 0.25 & Save and save temp \\
8 & 0.33 & Sort \\
26 & 1.08 & Logoff \\
25 & 1.04 & Null command \\
2404 & 100 & Total \\
\hline
\end{tabular}

accounted for $24 \%$ of pauses, and "type" for $14 \%$ of pauses. Together these three moves, plus "begin" which selects a database, accounted for $96 \%$ of all pauses.

The select and type/display commands are also the most ubiquitous in any search because of their inherent flexibility and centrality to the search task. We may suspect that the majority of pauses occurred in those moves because most subjects used only a small number of the available commands. Table 6 shows the command analysis. As expected, "select steps" or "select" accounted for the majority of commands ( 877 times, $40 \%$ ). Also, the "display" accounted for $26.7 \%$, and "type" for $15.1 \%$. The above three moves, plus "begin" which select a database, accounted for $88.7 \%$ of all moves. What is also apparent from this table is that the subjects used relatively few commands in their searches. Excluding "display sets" (148 times, 6.7\%) and "logoff" (80 times, $3.6 \%$ ), the other six commands accounted for only $0.9 \%$ of all commands. It can be concluded that

Table 6

Frequency distribution of moves and pauses

\begin{tabular}{lccc}
\hline Move & Frequency & Pause & Pause/frequency \\
\hline Begin & 151 & 114 & $75.5 \%$ \\
Select steps or select & 877 & 1273 & $145.2 \%$ \\
Display & 586 & 567 & $96.8 \%$ \\
Type & 332 & 333 & $100.3 \%$ \\
Expand & 2 & 1 & $50.0 \%$ \\
Display sets & 148 & 40 & $27.0 \%$ \\
Execute stop & 5 & 5 & $100.0 \%$ \\
Identify duplication or remove & 4 & 6 & $150.0 \%$ \\
duplication & & & \\
Save or save temp & 4 & 6 & $150.0 \%$ \\
Sort & 5 & 26 & $160.0 \%$ \\
Logoff & 80 & 2379 & $32.5 \%$ \\
Total & 2194 & & $108.4 \%$ \\
\hline
\end{tabular}


a small proportion of specific commands accounted for a large proportion of the command used. The results confirm Fenichel's (1981) findings.

Table 6 also shows that, in every move, searchers pause 1.08 times. People pause often in "select" command and some infrequently used commands, such as "save" and "sort" commands. While issuing one "select" command, searchers paused 1.5 times. The result confirms the difficulties in term selections and term operator selections for novice end-users. Selecting appropriate terms always requires good search strategies and search knowledge. No matter how familiar a searcher is with the search system, he still pauses in selecting terms. Among the other frequently used command, "display" and "type" accounted for $37 \%$ pauses. When issuing one "display" or one "type" command, searchers pause almost once. The result can be explained by the complexity of print command. It requires more information processing capacity especially for novice searchers. To correctly use the commands to display and type citation retrieved, a searcher needed to know the set number, print format, document number and the sequence in which to arrange these for a meaningful command that would have been accepted by the system.

\subsection{Amount of information being processed}

A pause is a discernible break in activity and presumably is related in some way to the activities that precede it. It can be regarded then as the final step in a series of steps that, for some reason or another, "hang together" for the searcher, i.e. they are unified and cling together. A chunk is defined as a pause and the moves or elements preceding it until the previous pause. The size of a chunk can be viewed as an indicator of information processing capacity of a subject. Drawing on data about the frequency of pauses, the average cycle, then, would have included five chunks of information, but may have included as few as none and as many as 34 .

The size of the chunk was measured by the number of elements. In this study, an element is any component of a command and its variable part, such as terms. It may consist of one or several keystrokes but the keystrokes are related. It is akin to a morpheme. For example, "d s1/5/all" consists of six elements (d,sl,/,5,/,all) and "ss expansion?" consists of three elements (ss, expansion, ?). Elements were used instead of commands because the subject frequently paused within commands, sometimes several times within the same command. They segmented the commands.

Studies of problem-solving have generally indicated that, although both novices and experts chunk information, and the number of chunks that can be processed is relatively invariant, the size of the chunks varies with the level of expertise of the problem-solver. Experts tend to integrate more information into a chunk than novices (Newell \& Simon, 1972). As expected, because most subjects were novice searchers, the size of most chunks was quite small. A chunk consisted, on the average, of six elements (the standard deviation is 8.9) (see Table 7). Almost 85\% of the chunks contained less than 10 elements and lasted less than 30 seconds. A few big chunks existed; for example, 30 chunks had more than 40 elements (maximum: 118).

\subsection{Hesitation rate}

The hesitation rate, or ratio between pausing and issuing commands (total pausing time divided by total user input time), indicates how tentatively a person moves online. The higher the ratio, the more time is spent in pausing. A hesitation ratio of 0.5 , for example, indicates that a searcher 
Table 7

Frequency distribution of size of chunk measured by number of elements

\begin{tabular}{lcc}
\hline Size of chunk (Elements) & Number of chunks & \% of total chunks \\
\hline $1-5$ & 1629 & 67.8 \\
1 & 597 & 24.8 \\
2 & 419 & 17.4 \\
3 & 285 & 11.9 \\
4 & 180 & 7.5 \\
5 & 148 & 6.2 \\
$6-10$ & 394 & 16.4 \\
$11-15$ & 155 & 6.4 \\
$16-20$ & 78 & 3.2 \\
$21-25$ & 63 & 2.6 \\
$26-30$ & 30 & 1.2 \\
$31-35$ & 17 & 0.7 \\
$36-40$ & 8 & 0.3 \\
$41+$ & 30 & 1.2 \\
Total & 2404 & 100.0 \\
\hline
\end{tabular}

spends equal time issuing commands and pausing between them. In this study, the hesitation rate per search ranged from 0.22 to 0.94 . The average hesitation rate per search was 0.68 while the standard deviation is 0.14 . On the average, the searchers in this study spent about $70 \%$ of their time online pausing instead of acting. More than half of the searches had hesitation rate between 0.6 and 0.8 (40 searches, 51\%). There were some extreme values: two were less than $0.4(3 \%)$ and four were greater than $0.9(5 \%)$. Again, the hesitation rate differs greatly across cycles in this study, although in over $75 \%(78.2 \%)$ of the cycles the searchers spent more time pausing than they do issuing commands (see Table 8), sometimes as much as $90 \%$. The average hesitation rate per cycle is 0.63 and the standard deviation is 0.19 . Although the distribution was scattered, the majority $(74 \%)$ fell within the range of $0.5-0.9$.

\subsection{Relationship between reasons for pausing and length of pause}

It is evident that composing search statements and choosing appropriate search terms are complicated tasks that may require longer processing time than determining the set number or deciding whether to use "sl" or " 1 ". The more complicated the decision, the longer the processing time is likely to be. Table 9 shows the average duration of the most frequently occurring pauses. The data show that subjects paused longer (greater than 8.8 seconds) when composing search statements, determining how to display, and confirming database numbers. Also, searchers had shorter pauses when determining the set number or item number for printing, deciding where to truncate, deciding upon spelling, and determining whether to space or not (these pauses averaged less than 6 seconds). Most findings confirm that the tasks that required more intellectual effort needed a longer time to process. Composing a search statement had the longest duration of pause, and checking the set number for "print" command and deciding which items to print had the shortest. 
Table 8

Frequency distribution of hesitation rates by cycles

\begin{tabular}{lcc}
\hline Hesitation rate per cycle & Number of cycles & Percentage \\
\hline $0.0-0.09$ & 4 & 0.9 \\
$0.1-0.19$ & 6 & 1.3 \\
$0.2-0.29$ & 17 & 3.6 \\
$0.3-0.39$ & 29 & 6.2 \\
$0.4-0.49$ & 46 & 9.8 \\
$0.5-0.59$ & 82 & 17.5 \\
$0.6-0.69$ & 105 & 22.4 \\
$0.7-0.79$ & 89 & 19.0 \\
$0.8-0.89$ & 70 & 15.0 \\
$0.9+$ & 20 & 4.3 \\
Total & 468 & 100.0 \\
\hline
\end{tabular}

Table 9

Most frequently occurring reasons for pausing ranked by average duration of pauses

\begin{tabular}{lcll}
\hline \multicolumn{2}{l}{ Duration of pause (s) } & & Most frequently occurring reasons for pausing \\
\cline { 1 - 2 } Mean & S.D & & \\
\hline 5.0 & 3.1 & & Determining the set number or checking the set number (for "print" command) \\
5.0 & 2.3 & & Determining which items to print \\
5.9 & 4.1 & & Determining where to truncate \\
5.9 & 3.6 & & Determining whether to put a space \\
6.0 & 3.8 & & Deciding upon spelling \\
6.4 & 5.5 & Verifying (proof reading) search statements \\
6.4 & 4.8 & Checking the set number already created (for "ss" commands) \\
6.9 & 5.1 & Determining whether to use this term (confirming the term) \\
7.2 & 5.7 & Determining how to display a specific item or a specific range of items (syntax) \\
7.5 & 7.5 & Deciding which term to use \\
8.0 & 8.6 & Deciding to use "and", making sure to use "and", or wondering whether to use "and" \\
8.4 & 8.2 & Deciding which print format to use or checking the print format \\
8.8 & 9.5 & Deciding the file number, getting the file number \\
9.0 & 8.1 & Determining how to display (syntax) \\
9.8 & 11.1 & Composing search statement (formulating search statement) \\
\hline
\end{tabular}

\subsection{Changes over time}

This study tests the general hypothesis that pausal behavior changes over time as searchers gain experience with searching tasks. The independent variable, search experience, is operationalized as the order of the search or the order of the cycle within a search. More specific hypotheses related to the characteristics of pausal behavior in this study are: as searchers progress through searches or cycles in a search, they pause less frequently and for shorter periods of time. Because searchers with more experience will move more smoothly online, so the hesitation rate per search (per cycle) will decrease over time. Over a series of searches or cycles, the chunks of information between pauses will increase. With more experience, end-users will become more fluent in formulating their search, as defined by the hesitation rate and smoothness of the interaction. 
Table 10

Average frequency of pause, average duration of pause, average hesitation rate per search, and average size of chunk preceding pause for first search and later searches

\begin{tabular}{|c|c|c|}
\hline \multirow[t]{2}{*}{ Search characteristics } & \multicolumn{2}{|l|}{ Searches } \\
\hline & First search & Later searches \\
\hline Average number of pauses per search ${ }^{* *}$ & $36.32(27.18)$ & $23.03(17.82)$ \\
\hline Average seconds per pause in a search ${ }^{* * *}$ & $8.92(11.12)$ & $7.40(8.27)$ \\
\hline Hesitation rate per search ${ }^{* * *}$ & $0.73(0.13)$ & $0.61(0.13)$ \\
\hline Average number of elements per chunk in a search ${ }^{* * *}$ & $5.57(7.85)$ & $7.58(10.65)$ \\
\hline
\end{tabular}

Notes: 1 . The ones marked with $* *$ in the table are significant at the 0.01 level. 2 . The ones marked with $* * *$ are significant at the 0.001 level. 3 . The standard deviation for each variable is indicated in parentheses below each average value.

Table 10 compares the first search with later searches. According to $t$-test results, all hypotheses are fully supported at least the 0.01 level. Table 10 shows subjects paused on the average about 36 times in their first searches. Each pause lasted about 9 seconds. The hesitation rate was 0.73 , which was slightly higher than the average hesitation rate of all searches (0.68). Between each pause the searcher issued an average of six elements. In later searches, the number of pauses dropped by almost a third (23). The duration of the pause was less but not markedly so, about 7.5 seconds instead of the 9 seconds in the first search. The hesitation rate declined by about 16\%. The searchers chunked larger amounts of information between pauses (about eight elements instead of six). The results confirm Yuan's (1997) findings that search experience affected several aspects of end-users behavior, including the increase of search speeds.

Table 11 compares the first cycle with later cycles. According to ANOVA test results, all hypotheses are fully supported at least the 0.001 level with the exception of the hypothesis related to length of pauses. The data across the six cycles show that improvement began to occur even in the first few cycles. From learning theory, the most common finding in instrumental learning is that the response builds up rapidly and then levels off (Houston, 1981). According to the phenomenon, improvement is more apparent in the early stages. In the first cycle, the subjects paused on the average about 10 times during a cycle. Each pause lasted about 9 seconds. The hesitation rate was 0.71. Between each pause the searchers issued an average of 4 elements. In the sixth or later cycles, the number of pauses dropped by almost two-thirds to 3 pauses during a cycle. The duration of pause was slightly less, about 8.26 instead of 9 seconds. The hesitation rate declined by about $20 \%$.

Comparing the first cycle with the sixth cycle, the searchers chunked larger amounts of information between pauses, measured in number of elements (about nine elements instead of four). In the first cycle, for example, a print command of " $t / \mathrm{s} 5 / 9 /$ all" may have been chunked as " $t$ - $-\mathrm{s} 5$ -/- -9--/--all" (worst case, six chunks, one element per chunk). After one or two cycles, it may have been chunked as "t s5/--9/all" (two chunks, each chunk with more elements). Fig. 3 shows two consecutive cycles in the same search with pauses noted.

An interesting phenomenon is appeared in Table 11. The size of a chunk and the hesitation rate reached maximum capacity in the fourth cycle. By the fifth cycle, the size of the chunk actually declined, and the hesitation rate stabilized. The notion of cognitive load offers an explanation for this apparent stability. Cognitive overload is likely to happen in a person with less experience. In the beginning searches or cycles in this study, operating basic search commands may have 
Table 11

Average frequency of pause, average duration of pause, average hesitation rate per cycle, and average size of chunk preceding pause for first cycle through sixth and later cycles

\begin{tabular}{lllllll}
\hline & \multicolumn{6}{l}{ Cycles } \\
\cline { 2 - 7 } & 1st & 2nd & 3rd & 4th & 5th & 6th \\
\hline $\begin{array}{l}\text { Average number of pauses per } \\
\text { cycle }\end{array}$ & $9.84(8.17)$ & $5.09(5.53)$ & $5.57(5.28)$ & $4.37(4.39)$ & $4.05(3.85)$ & $3.20(3.10)$ \\
$\begin{array}{l}\text { Average second per pause in a } \\
\text { cycle }\end{array}$ & $8.97(11.36)$ & $8.63(9.90)$ & $7.63(6.93)$ & $8.38(9.60)$ & $7.46(8.58)$ & $8.26(11.46)$ \\
$\begin{array}{l}\text { Hesitation rate per cycle } \\
\begin{array}{l}\text { Average number of elements per } \\
\text { chunk in a cycle }\end{array}\end{array}$ & $0.71(0.16)$ & $0.67(0.18)$ & $0.64(0.19)$ & $0.58(0.17)$ & $0.58(0.16)$ & $0.57(0.19)$ \\
\hline
\end{tabular}

Notes: 1 . The ones marked with $* * *$ are significant at the 0.001 level. 2 . The standard deviation for each variable is indicated in parentheses below each average value.

\begin{tabular}{|c|c|}
\hline Cycle 1: [8 pauses] & Cycle 2: [2 pauses] \\
\hline Searcher: b 622 [no pause here] & Searcher: b 612 [no pause here] \\
\hline Searcher: ss [4 sec.] zaibatsu & Searcher: ss zaibatsu \\
\hline Searcher: d [4 sec.] s1/ [4 sec.] 5/all & Searcher: d s1/ [9 sec.] 3/all \\
\hline Searcher: $\mathrm{d}$ s $1 / 3$ [3 sec.] /all & Searcher: d s1/ [4 sec.] 5/1,3,4,5 \\
\hline $\begin{array}{r}\text { Searcher: type }[25 \mathrm{sec} .] \mathrm{s} 1[3 \mathrm{sec} .] /[3 \\
\text { Sec.] / 1,2,4,6,11,15 [9 sec.] }\end{array}$ & Searcher: $\mathrm{t}$ s $1 / 5 / 1,3,4,5$ [no pause here] \\
\hline -- hesitation rate: .83 & --hesitation rate: .78 \\
\hline $\begin{array}{l}\text {--average size of a chunk [by elements]: } \\
4.38\end{array}$ & $\begin{array}{l}\text {--average size of a chunk [by elements]: } \\
7.0\end{array}$ \\
\hline $\begin{array}{l}\text {--average size of a chunk [by time]: } 12.65 \\
\text { sec. }\end{array}$ & $\begin{array}{l}\text {--average size of a chunk [by time]: } 20.16 \\
\text { sec. }\end{array}$ \\
\hline
\end{tabular}

Fig. 3. Progress through two different cycles in same search: search example.

occupied a large amount of information processing capacity, so less capacity was available for other competing commands of the search system. As searchers became more familiar with the basic search commands, they freed capacity to explore other commands or features. But, as the searchers experimented with new commands or features, more information processing capacity again had to be focused on the new features, and they were not able to chunk as much information as before. This result also reflects an inverted-U effect as many phenomena, such as activation level and performance efficiency (Hebb, 1955), conflict level and the number of new actions and the improvement of accuracy of the interpretation (Chalidabhongse, 2000). The inverted-U curve also describes the pausal behavior, i.e. learners' success rate actually goes down as they make adjustment to analyzing problem using new paradigm, then goes up when this paradigm mastered, goes down again when they explores other features of the system. 
The length of pause does not vary significantly across cycles, indicating perhaps that, for some pauses, task-related factors may contribute to length differences within a search. The same task may require similar time regardless of where it appears in a search. In a study of pausing during a writing task, however, pause location was found to be relative weak predictor of pause duration variations (Foulin, 1998).

In this study, the percentage distribution of types of pause across early and later searches were quite similar. For both first searches and later searches, almost $35 \%$ of all pauses related to display and type, $15 \%$ to term selection, and $13 \%$ to term operators. Table 12 shows the percentage distributions of type of pause among different cycles. In the first cycle, the subjects paused more frequently in problems related to selecting databases, issuing ss commands, printing records, and choosing term operators. After several cycles, pauses moved to problems relating to choosing terms, refining search statements, doing other field searches, and "moving-forward" with a search. Although the results may be due to the natural progression of a search, they show more specifically that, in the first few cycles (especially the first), searchers paused more about syntax

Table 12

Frequency distribution of types of pauses for first cycle through sixth and later cycles

\begin{tabular}{|c|c|c|c|c|c|c|c|}
\hline & \multicolumn{7}{|l|}{ Cycles } \\
\hline & $1 \mathrm{st}$ & 2nd & $3 \mathrm{rd}$ & 4th & 5 th & 6 th + & Total \\
\hline $\begin{array}{l}\text { (a) Pauses related to } \\
\text { "begin" a database*** }\end{array}$ & $\begin{array}{l}50 \\
(6.4 \%)\end{array}$ & $\begin{array}{l}9 \\
(2.5 \%)\end{array}$ & $\begin{array}{l}14 \\
(3.9 \%)\end{array}$ & $\begin{array}{l}7 \\
(3.0 \%)\end{array}$ & $\begin{array}{l}5 \\
(3.0 \%)\end{array}$ & $\begin{array}{l}10 \\
(2.0 \%)\end{array}$ & $\begin{array}{l}95 \\
(4.0 \%)\end{array}$ \\
\hline $\begin{array}{l}\text { (b) Pauses related to ss } \\
\text { command }^{* * *}\end{array}$ & $\begin{array}{l}79 \\
(10.1 \%)\end{array}$ & $\begin{array}{l}27 \\
(7.5 \%)\end{array}$ & $\begin{array}{l}27 \\
(7.6 \%)\end{array}$ & $\begin{array}{l}17 \\
(7.4 \%)\end{array}$ & $\begin{array}{l}15 \\
(9.0 \%)\end{array}$ & $\begin{array}{l}41 \\
(8.0 \%)\end{array}$ & $\begin{array}{l}206 \\
(8.6 \%)\end{array}$ \\
\hline $\begin{array}{l}\text { (c) Pause related to } \\
\text { choosing terms }\end{array}$ & $\begin{array}{l}76 \\
(9.8 \%)\end{array}$ & $\begin{array}{l}74 \\
(20.6 \%)\end{array}$ & $\begin{array}{l}69 \\
(19.3 \%)\end{array}$ & $\begin{array}{l}60 \\
(26.0 \%)\end{array}$ & $\begin{array}{l}35 \\
(21.0 \%)\end{array}$ & $\begin{array}{l}74 \\
(14.5 \%)\end{array}$ & $\begin{array}{l}388 \\
(16.1 \%)\end{array}$ \\
\hline $\begin{array}{l}\text { (d) Pauses related to } \\
\text { "display" or "type" }{ }^{* * *}\end{array}$ & $\begin{array}{l}306 \\
(39.3 \%)\end{array}$ & $\begin{array}{l}147 \\
(40.8 \%)\end{array}$ & $\begin{array}{l}112 \\
(31.4 \%)\end{array}$ & $\begin{array}{l}65 \\
(28.1 \%)\end{array}$ & $\begin{array}{l}58 \\
(34.7 \%)\end{array}$ & $\begin{array}{l}167 \\
(32.7 \%)\end{array}$ & $\begin{array}{l}855 \\
(35.6 \%)\end{array}$ \\
\hline $\begin{array}{l}\text { (e) Pauses related to } \\
\text { using term operators }{ }^{* * *}\end{array}$ & $\begin{array}{l}109 \\
(14.0 \%)\end{array}$ & $\begin{array}{l}47 \\
(13.1 \%)\end{array}$ & $\begin{array}{l}46 \\
(12.9 \%)\end{array}$ & $\begin{array}{l}27 \\
(11.7 \%)\end{array}$ & $\begin{array}{l}17 \\
(10.2 \%)\end{array}$ & $\begin{array}{l}65 \\
(12.7 \%)\end{array}$ & $\begin{array}{l}311 \\
(12.9 \%)\end{array}$ \\
\hline $\begin{array}{l}\text { (f) Pauses related to } \\
\text { refining a search* }\end{array}$ & $\begin{array}{l}18 \\
(2.3 \%)\end{array}$ & 7 & 8 & $\begin{array}{l}9 \\
(3.9 \%)\end{array}$ & $\begin{array}{l}9 \\
(5.4 \%)\end{array}$ & $\begin{array}{l}9 \\
(1.8 \%)\end{array}$ & $\begin{array}{l}60 \\
(2.5 \%)\end{array}$ \\
\hline $\begin{array}{l}\text { (g) Pauses related to } \\
\text { "field search" }{ }^{* *}\end{array}$ & $\begin{array}{l}62 \\
(8.0 \%)\end{array}$ & $\begin{array}{l}21 \\
(5.8 \%)\end{array}$ & $\begin{array}{l}44 \\
(12.3 \%)\end{array}$ & $\begin{array}{l}15 \\
(6.5 \%)\end{array}$ & $\begin{array}{l}11 \\
(6.6 \%)\end{array}$ & $\begin{array}{l}53 \\
(10.4 \%)\end{array}$ & $\begin{array}{l}206 \\
(8.6 \%)\end{array}$ \\
\hline $\begin{array}{l}\text { (h) Pauses related to } \\
\text { getting help }\end{array}$ & $\begin{array}{l}22 \\
(2.8 \%)\end{array}$ & $\begin{array}{l}8 \\
(2.2 \%)\end{array}$ & $\begin{array}{l}10 \\
(2.8 \%)\end{array}$ & $\begin{array}{l}4 \\
(1.7 \%)\end{array}$ & $\begin{array}{l}5 \\
(3.0 \%)\end{array}$ & $\begin{array}{l}29 \\
(5.7 \%)\end{array}$ & $\begin{array}{l}78 \\
(3.2 \%)\end{array}$ \\
\hline $\begin{array}{l}\text { (i) Pauses related to } \\
\text { "moving forward" with } \\
\text { a search }\end{array}$ & $\begin{array}{l}54 \\
(6.9 \%)\end{array}$ & $\begin{array}{l}19 \\
(5.3 \%)\end{array}$ & $\begin{array}{l}25 \\
(7.0 \%)\end{array}$ & $\begin{array}{l}22 \\
(9.5 \%)\end{array}$ & 9 & $\begin{array}{l}53 \\
(10.4 \%)\end{array}$ & $\begin{array}{l}182 \\
(7.6 \%)\end{array}$ \\
\hline $\begin{array}{l}\text { (j) Pauses related to } \\
\text { "logoff" }\end{array}$ & $\begin{array}{l}3 \\
(0.4 \%)\end{array}$ & $\begin{array}{l}1 \\
(0.3 \%)\end{array}$ & $\begin{array}{l}2 \\
(0.6 \%)\end{array}$ & $\begin{array}{l}5 \\
(2.2 \%)\end{array}$ & $\begin{array}{l}3 \\
(1.8 \%)\end{array}$ & $\begin{array}{l}9 \\
(1.8 \%)\end{array}$ & $\begin{array}{l}23 \\
(1.0 \%)\end{array}$ \\
\hline Total & $\begin{array}{l}779 \\
(32.4 \%)\end{array}$ & $\begin{array}{l}360 \\
(15.0 \%)\end{array}$ & $\begin{array}{l}357 \\
(14.9 \%)\end{array}$ & $\begin{array}{l}231 \\
(9.6 \%)\end{array}$ & $\begin{array}{l}167 \\
(6.9 \%)\end{array}$ & $\begin{array}{l}510 \\
(21.2 \%)\end{array}$ & $\begin{array}{l}2404 \\
(100 \%)\end{array}$ \\
\hline
\end{tabular}

Notes: 1 . Types of pauses marked with $*$ in the table are significant at the 0.05 level, the one with $* *$ at the 0.01 level, and the one with $* * *$ at the 0.001 level. 2. The percentage for each value is indicated in parentheses. 
decisions. As their experience increased, their ability with the syntax, especially the basic commands and command formats, grew, and they could allocate more cognitive capacity to the more variable aspects of the messages, such as the search terms. Also, by the fourth cycle, the searchers seemed to have become sufficiently familiar with basic search elements to explore other system features. By that stage fewer pauses were related to display and type, but more were related to selecting terms and refining search statements.

\section{Discussion}

Searching for information online is a complex task, especially for novice searchers. Besides the normal cognitive demands of formulating a strategy and expressing in search terms combined with Boolean logic, they also must cope with the syntax of a foreign language. The latter entails not only the specific search terminology and functions but also the arrangement and punctuation of the search statement. Perhaps the most significant finding in this study is that searchers became more fluent relatively quickly. Change was obvious even across cycles within the same search, as Fig. 3 indicates. Nevertheless, on average, over half of their time was spent in pausing, although their hesitation rates declined as they gained experience.

Some of this increase in fluency was due, no doubt, to the fact that the subjects confined themselves to relatively few, albeit powerful, command (see Table 6). Even the few they used cause them to pause while using them. For example, as the element analysis indicated, some subjects were confused about "ss" commands, even about $50 \%$ of the searchers had searched before on CD-Roms; many of the CD-Rom searching have not to remember which command allowed him to develop a set, he also had to reject a familiar tendency and actually use a command for this function.

That subjects paused often as they were selecting terms (1273 times, 53\%) is not surprising. The choice of commands may be fairly limited and decisions regarding them are likely, in the long run, to become somewhat familiar, but search terms change according to the situation in very significant ways, probably always necessitating pauses during the task. Selecting appropriate terms requires subject knowledge, the ability to think flexibly about term relationships, and understanding the implications of variant ways of phrasing the terms. Even experienced searchers are likely to pause while selecting terms. In addition, pauses relating to composing a search statement, including selection of search terms were among the longest pauses seen in the study (Table 9). The relatively invariant length of time associated with reasons for pausing suggests that task-related factors may be more influential than experience in explaining pause length.

The adaptability of the searchers to the cognitive loads they faced showed in several instances, most notably in connection with the "display" and "type". In Dialog, the two are complex commands. At least a quarter of the pauses were related to "display" or "type" (900 pauses, $37.4 \%$ ). To correctly use the search system commands to display or type citations retrieved, a searcher needed to know the set number, print format, document number and the sequence in which to arrange these, and the punctuation. These elements constitute a large cognitive load for novice users. In addition, for both set and items, they either had to note the relevant set numbers or item numbers during the searches or check back to verify the information. Even within the 
syntax, the range of options is large. In this study, some subjects lessened the cognitive load by eliminating some of the decisions associated with printing or typing. They discovered that, by using " $t$ " or " $d$ " for the commands "type" or "display", they could see one citation at a time. Instead of programming beyond the default options, they simply continued to type sequential d's or t's to see the desired citations.

Previous studies of end-user searching behavior based on error analysis have indicated that searchers have difficulty with Boolean logic (Borgman, 1984). Although this study does not analyze search transcripts and search results to determine the level of the search's success, the subjects' pausing behavior confirms that the subjects paused frequently in connection with search logic (including using Boolean operators, the proximity operator, and parentheses). Again some searchers may have been adjusting mental models developed through use of other systems. Most of the subjects indicated some experience with the local OPAC. At Maryland, the OPAC interprets words entered without logical operators as "anded" terms.

The Dialog system is not designed for end-users, even though end-users can still learn to use it. The commands used in Dialog system are quite different compared to CD-Rom systems or network environment. Some pauses identified from this study are independent of search systems. Those pauses that are not related to system can arise in other system, such as determining where to truncate, deciding upon spelling, determining whether to use this term or not, etc. But, some pauses that are related to Dialog syntax will not occur in other search systems, such as those pauses related to type and display commands.

Another especially important finding is that the subjects processed relatively small chunks of information, although size of chunks would lengthen over cycles. They paused often within commands and tended to pause as they are issuing an element, not to think back, or to plan ahead several moves. The latter suggested that one potential use of monitoring pausing data is to identify places where help could be suggested automatically. A longer pause, for example, might trigger advice about the likely decisions at that point.

While some of the findings corroborate and support what have already been discovered about novice searchers using command systems, nevertheless, this study adds a level of detail and refinement to previous findings. The findings here, for example, can reach the level of identifying potentially problematic areas within a particular command or show how quickly novice searchers inculcate basic syntax into their searching patterns.

In web-based environment, there are fewer and fewer command-based information retrieval systems. Thus, it becomes the major limitation of this article. However, most findings can still help the Dialog to improve its command-based system. Also, findings are independent of command system can be applied to general IR systems. More important, pausal behavior can always identify the potential problem areas of users, especially for some decisions requiring more information processing capacity even in web-based IR systems.

\section{Usefulness of studying pausal behavior}

This study marks the first time that pausal behavior has been emphasized in studying online searching behavior, although time-related behavior in the form of response times has been studied in connection with other computer tasks. 
Pauses are sensitive indicators of task areas, subtasks, or command which require greater information processing. They may denote complex or unanticipated demands on the information processing capacity of the individual involved in a task. A person may pause, for example, to recall information, to react to unexpected output, to confirm an action, to consider alternative actions and plan, to retrieve information from external sources, or to assimilate information.

Although some pauses are associated with errors, the pause is far more ubiquitous. As a result, analyzing pausal behavior provides insights not only into decision-making resulting in actual errors, but also into decisions which are more complex or which result in information which is unexpected. It may provide the basis, therefore, for identifying potential problem areas. In addition, the approach offers promise for studying information processing capacity which other methods cannot provide. In this study, for example, it was possible, through looking at pauses, to characterize the length and size of chunks. Pausing time can be precisely calculated from timed keystroke data. Since human-interaction labs regularly collect keystroke data, they should consider augmenting this data by analyzing timed keystroke data to identify pauses both between and within commands. Precisely measured pauses, used in conjunction with error analysis, for example, may be helpful in distinguishing between errors and slips (Norman, 1981).

Unfortunately keystroke capture programs cannot note pauses during all subtasks within a search. They cannot, for example, register the pauses that occur as an individual reads the system output, but they can readily identify pauses when a searcher is inputting commands, even those of relatively short duration (see Fig. 2). As this study has shown, however, the reason for pausing cannot always be inferred from observations, nor can the person performing the task always remember the reason or reasons for pausing even when given the context for the pause shortly after completing the task. But, in this study, after searchers saw the computer output, they could recall their reasons for pausing. Nevertheless, these problems do not erase the potential benefits of gathering data on pauses within a task.

Determining the size of the pause to be studied in characterizing pausal behavior is not simple since individual differences may figure prominently in the length of a pause. In a study of more experienced online searchers, for example, limiting relevant pauses to those three seconds or longer, as in this study, may greatly underrepresent the actual pausing that occurs. Ideally, a pause should be identified as any significant change in a search rhythm for an individual. Continued study of pauses should provide additional insights into its usefulness for understanding the information processing occurring during computer-related tasks.

Pausal behavior provides insight into an individual's information processing as he proceeds through a particular task. In a computer environment, much emphasis has been placed on analyzing errors or patterns of commands as a means of gaining insights into the mental models individuals operate under in doing a task (Borgman, 1984; Norman, 1983). Pausal analysis provides a basis for additional insights into human behavior.

\section{Acknowledgement}

The author acknowledges the inspiration, assistance, and the contribution of Marilyn D. White to the development of this research. 


\section{References}

Borgman, C. L. (1984). The user's mental model of an information retrieval system: Effects on performance. Ph.D. dissertation, Stanford University.

Carter, R. F., Ruggels, W. L., Jackson, K. M., \& Heffner, M. B. (1973). Application of signaled stopping technique to communication research. In P. Clarke (Ed.), New models for mass communication research (pp. 15-43). Beverly Hill, California: Sage Publication.

Chalidabhongse, J. (2000). Modeling complexity in organizational dynamics: Organizational learning and conflict. Dissertation Abstracts International: Section B: The Sciences and Engineering, 61(1-B), 463.

Charles, K. S., \& Clark, K. E. (1990). Enhancing CD-ROM searches with online updates: An examination of end-user needs, strategies, and problems. College and Research Libraries, 51, 321-328.

Fenichel, C. H. (1981). Online searching measures that discriminate among users with different types of experiences. Journal of American Society for Information Science, 32(January), 23-32.

Foulin, J. (1998). To what extent does pause location predict pause duration in adults' and children's writing? Cahiers de Psychologie Cognitive, 17(3), 601-620.

Grunig, J. E. (1985). An axiomatic theory of cognition and writing. Journal of Technical Writing and Communication, $15,95-130$.

Hebb, D. O. (1955). Drives and the conceptual nervous system. Physiology Behavior Review, 62, 243-254.

Houston, J. P. (1981). Fundamentals of learning and memory. New York: Academic Press.

Kirby, M., \& Miller, N. (1986). Medline searching on colleague: Reasons for failure or success of untrained end user. Medical Reference Services Quarterly, 5, 17-34.

Miller, G. A. (1956). The magic number seven, plus or minus two: Some limits of capacity for processing information. Psychology Review, 63, 81-97.

Newell, A., \& Simon, H. A. (1972). Human problem solving. Englewood Cliffs, NJ: Prentice-Hall.

Norman, D. A. (1981). Categorization of action slips. Psychological Review, 88, 1-15.

Shaw, D. (1986). Nine sources of problems for novice online searchers. Online Review, 10, 295-303.

Tavalin, F. (1995). Context for creativity: Listening to voices, allowing a pause. Journal of Creative Behavior, 29(2), 133-142.

Tenopir, C. (1986). Four options for end user searching. Library Journal, 111, 56-57.

Trzebiatowske, E. (1984). End user study on BRS/after dark. RQ, 23, 446-450.

Yuan, W. (1997). End-user searching behavior in information retrieval: A longitudinal study. Journal of the American Society for Information Science, 48, 218-234.

Walker, C. J., McKibbon, K. A., Hayes, R. B., \& Ramsden, M. F. (1991). Problems encountered by clinical and users of MEDLINE and GRATEFUL MED. Bulletin of Medical Library Association, 79, 67-69.

Wozny, L. A. (1988). College students as end user searchers: One university's experience. $R Q, 28,54-61$.

\section{Further reading}

Collet, C., Roure, R., Rada, H., Dittmar, H., \& Vernet-Maury, E. (1996). Relationships between performance and skin resistance evolution involving various motor skills. Physiology and Behavior, 59(4-5), 953-963.

Huang, M. (1992). Pausing behavior of end-users in online searching. Ph.D. dissertation, The University of Maryland.

Kantor, P. B. A. (1987). A model for the stopping behavior of users of online systems. Journal of American Society for Information Science, 38(May), 211-214.

Norman, D. A. (1983). Some observations on mental models. In D. Gentner \& A. S. Stevens (Eds.), Mental models (pp. 7-14). Hillsdale, NJ: Lawrence Erlbaum Association.

Saracevic, T., Kantor, P., Chamis, A. Y., \& Trivison, D. (1988). A study of information seeking and retrieving I. Background and methodology. Journal of American Society for Information Science, 39(May), 177-196.

Saracevic, T., \& Kantor, P. (1988a). A study of information seeking and retrieving. II. Users, question, and effectiveness. Journal of American Society for Information Science, 39(May), 177-196. 
Saracevic, T., \& Kantor, P. (1988b). A study of information seeking and retrieving. III. Searches, searches, and overlap. Journal of American Society for Information Science, 39(May), 197-216.

Spink, A., \& Saracevic, T. (1997). Interaction in information retrieval: Selection and effectiveness of search terms. Journal of the American Society for Information Science, 48, 741-761.

Susan, S., Marcia, J. B., \& Deborah, N. W. (1993). A profile of end-user searching behavior by humanities scholars: The getty online searching project report no. 2. Journal of the American Society for Information Science, 44(June), 273-291. 